\title{
Using Audio-Visual Aids and Computer-Assisted Language Instruction (CALI) to Overcome Learning Difficulties of Reading in Students of Special Needs
}

\author{
Sadeq Ali Saad Al- Yaari \\ Independent Researcher, Dept. of English, College of Arts, King Saud University (KSU) \\ Riyadh, Kingdom of Saudi Arabia \\ E-mail: prof.sadeq@gmail.com
}

Received: October 28, 2013 Accepted: November 10, 2013 Published: December 12, 2013

doi:10.5296/jsel.v1i2.4741 URL: http://dx.doi.org/10.5296/jsel.v1i2.4741

\begin{abstract}
Background \& aims: Reading is a receptive skill whose importance could involve abilities' variance from linguistic standard. Several evidences support the hypothesis stating that the more you read the better you write, with a different impact for speech language therapists (SLTs) who use audio-visual aids and computer-assisted language instruction (CALI) and those who do not.

Methods: Here we made use of audio-visual aids and CALI for teaching reading skill to a group of 40 students of special needs of both sexes (range between 8 and 18 years old) at al-Malādh school for teaching students of special needs in Dhamar (Yemen) while another group of the same number is taught using ordinary teaching methods. Pre-and-posttests have been administered at the beginning and the end of the semester (Before and after teaching the reading course). The purpose was to understand the differences between the levels of the students of special needs to see to what extent audio-visual aids and CALI are useful for them. The two groups were taught by the same instructor under the same circumstances in the same school. Both quantitative and qualitative procedures were used to analyze the data.

Results: The overall findings revealed that audio-visual aids and CALI are very useful for teaching reading to students of special needs and this can be seen in the scores of the treatment group's subjects $(25.77 \%$, in post-test vs. $70.92 \%$ in pre-test). In comparison to the scores of the second group's subjects (where audio-visual aids and CALI were not used) ( $22 \%$ in both pre-and-posttests), the first group subjects have fully understood the material of reading and this can be observed in their performance in the posttest. In addition, compared with males, females' performance was better (1371 scores vs. 1466 scores). Qualitative and
\end{abstract}


statistical analyses showed that such comprehension is absolutely due to the use of audio-visual aids and CALI and nothing else. These outcomes confirm the evidence of the significance of using audio-visual aids and CALI as effective means for teaching receptive skills in general and reading skill in particular.

Keywords: Reading, Receptive Skills, Audio-Visual Aids, CALI, Students, Special Needs, SLTs

\section{Introduction Chapter}

\subsection{Introduction}

Audio-visual aids and CALI are associated with the improvement of language skills be it receptive skills or productive skills or even language components (Gilakjani, 2012). These educational aids are found to be useful not only for normal students, but also for students with special needs (Iram, 2012; Kirk, et al., 2012). Explaining the reasons behind the new trend, Kirk and his colleagues have rightly observed: "Such tests, in which acoustic variability is highly constrained, may not accurately reflect spoken word recognition abilities under more natural listening situations." (Kirk, et al., 2012: p. 455)

To study how audio-visual aids and CALI affect the ability of the normal students and those of special needs, improve their productive skills, some researchers went further to investigate the process of recognizing the word in the brain before it is articulated. According to them, articulation is the ice-berg of the pronunciation process which is preceded by brain process Bradham (2012). The operation takes place, according to Bradham when "Outer hair cells provide mechanical feedback into the organ of Corti, thus enhancing the input to the inner hair cells, which predominantly send information to the central nervous system." (Bradham, 2012: Abstract)

Such findings inspired researchers to ask legitimate and reasonable questions relating to the ways information are processed in the brain and the relationship between motion representation and the visual motion system (Pavan \& Baggio, 2013). More importantly, how and where does this process take place in the brains of students with special needs, especially when it comes to matters relating to deep/ surface reading for example (Wolf, et al., 2012) or those concerning Braille-reading and the way to understand issues like shape and space by blind students (Klingenberg, 2013). Onnis \& Thiessen (2013)'s findings suggest that mechanisms of statistical sequential learning are implicated in language across the lifespan, and experience with language may affect cognitive processes and later learning. Others went further by investigating not only the patients, but also the role of the parents and other people around the child which results "in greater exposure to the majority language." (MacLeod, et al., 2013: p. 132) New trends of the research in this field started to focus on physicians and nurses and the way they read, write, etc. (Khaliq, et al., 2012; Peinhardt \& Hagler, 2013). Furthermore, scientists established a new trend whereby language aspects could be linked together. The study of Diaz-Maurin \& Giampietro (2013) investigated the impact of grammar for assessing the performance of power-supply systems. Having the nuclear energy and fossil 
energy compared to each other, the researchers concluded that when considering internal constraints, nuclear energy requires about twice as much power capacity and 5-8 times more labor. Diaz-Maurin and his colleague confirmed that things do not improve for nuclear energy when looking at external constraints which may explain the difficulties faced by nuclear energy to gain interest from investors.

Despite of the fact that audio-visual aids and CALI made better progress in the levels of students, some researchers are still believe in the original methods as effective means through which students can acquire language skills, notably reading, listening and writing (Devimeenakshi \& Maheswari, 2012). Additionally, pedagogical-based aids were present with more theoretical views but not with more practical use. Consistent with the existing literature on other audio-visual aids and CALI, at least film is common in the field of education (Swimelar, 2013)

Knowing the prevalence of boards, notably for teaching students of special needs supplements educational interpretation and can overcome the learning difficulties they suffer from? Many studies have been conducted in this field like Gessesse \& Sileshi (2013)'s study whose purpose was to examine visual semiotic signs and bill-boards and their communication implications, especially if they are used for patients. It appears to in favor of this that Gessesse and her friend have forwarded the following notification: "all the visual semiotic signs on all these billboards would give a much wider picture of the types and applications of visual semiotic signs. For another, it would also provide greater opportunities to identify the genres of messages represented through these visuals semiotic signs." (Gessesse \& Sileshi, 2013: p. 246)

Students of special needs frequently encounter learning difficulties related to audio, visual or audio-visual texts. Some difficulties can be subtle but can seriously influence the students' ability to learn. The article of Brown et al., (2013) proposes that differing types of annotation offer a powerful and flexible technique for transferring the benefits of graph-based diagrams, as well as for reducing disorientation while moving around the graph and for tackling some of the inherent disadvantages of using sound. According to Brown and his friends, graph annotation may be performed automatically, creating a graph that evaluation shows requires less mental effort to explore and on which tasks can be achieved more effectively and more efficiently. Such results received high support from Chen \& Yen (2013) who concluded their study by providing insights on the design and instruction, not only for written text reading, but also for online reading.

The technological features of reading software that can be used for word recognition have not been explicitly investigated, but they may not be comparable because some techniques do not follow the same distinctive features and other qualities of others. The study of Damoiseaux, et al., (2012) may be a valuable source of information for refining our understanding of some of this software in general. Damoiseaux and his friends discussed the automatic reading of anti-neutrophil cytoplasmic autoantibody (ANCA-Slides). The purpose of the research team was to evaluate the AKLIDES System. The research team emphasized that the results are promising in that the pattern recognition may play an important role in ANCA-associated 
vasculitis diagnostics. Explaining the reason that might stand behind the success of AKLIDES system, the research team has clearly stated: "Apparently, changes in the software of the AKLIDES system enable to improve correct pattern recognition." (Damoiseaux, et al., 2012: p. 6)

Some researchers investigated the idea of how blogs could be used for language purposes. The article of Álvarez (2012), for example, presents a study on the best ways of using blogs as a tool to improve students' reading and writing skills. According to the researcher, "....blogs usually includes information about the user, a categorization of each post and links to other websites." (Álvarez, 2012: p. 188)

The results showed that blogs are reliable tools for the improving students' productive skills. A total of 186 English as second language (ESL) elementary school subjects underwent the study of Ismail, et al, (2012). The aim of the study was to dis/prove whether or not using technology helps ESL learners improve their reading and writing skills. There are significant differences in the performances of the ESL students. This can be obviously seen in the outcomes of the qualitative and quantitative analyses of the scores. According to Ismail and his team, technology might play crucial role in assisting students to learn reading and writing skills. Other significant results, the researchers added, revealed that technology helped teachers in assigning extracurricular activities and communicating with students.

There has been growing interest recently in the use of multimedia as audio-visual aids to decode information and facilitate messages from high-dimensional scientific facts and present them to English as foreign language (EFL) students. The study of Fuenzalida \& Sjöberg (2012) employed a support vector machine-based T.V approach to teach EFL students language skills, especially for young learners. Such results were supported by the study of Ahmed (2012). Gower \& McDowall (2012) assessed the role of interactive video games on educating children during the study of language skills and/ or language components. Eleven subjects ( 9 children and 2 music specialists) underwent the experiment. The two researchers concluded their study by recommending the use of audio-visual aids and computer-assisted/ aided language instruction (CALI) as useful educative means when they are used for teaching EFL students.

In their study, Anson \& Schwegler (2012) aimed at investigating tracking mind's eye technique. Anson and his colleague wanted to examine the usefulness of this strategy to be implemented for improving foreign language students' reading skill. Nevertheless, the study also highlighted the need for further research into how to improve such technique in composition studies, especially at the intersection of writing. Although currently only a few randomized controlled studies investigated the efficacy of tracking the movement of the eye, such outcomes received a great support by many researchers in the field who conducted similar studies (Henderson \& Luke, 2012; Perea, 2012).

Audio-visual aids and CALI had a strong internal and external consistency on the performance of the students. The test-retest and intra- and inter-rater reliabilities were shown to be adequate when it comes to talk about the effectiveness of the audio-visual aids and CALI, and the same thing applies to discriminant validity which was good in most of the 
conducted studies. For new techniques related to audio-visual aids and CALI, different outcomes were found: apart from one correlation, the scores on tests assessing a language skill and/ or a language component correlated significantly with outcome measures of similar methods. One of those methods is graphic organizer method designed by Manoli \& Papadopoulou in 2012. According to the researchers, the study constitutes an attempt to shed light on the research evidence regarding the effectiveness of graphic organizer on text learning and the various types of graphic organizers, which use different conventions to communicate information and are classified in various ways. Moreover, such strategy can be used "both in the teaching and learning of languages and in content areas, like science, social studies." (Manoli \& Papadopoulou, 2012: Introduction)

The researchers finished their study by recommending ways of integrating them in reading lessons, touches on the issue of strategy instruction and its effects on language learning and leaves room for further exploration.

Shelley-Tremblay, et al., (2012) measured the effects of attention therapy in the improvement of reading skill in the juvenile. The scores of 42 subjects (19 of them are the treatment group and 23 are the control group) were computed for an attempt to in/validate the assumption that therapy may play an important role in compensating the weakness in language abilities and/ or skills. Across different changes from the viewpoints, the overall results drawn from the study of Shelley-Tremblay and his friends showed significantly greater increase in reading comprehension than a normal education control. This study provided normative data for changes in the different points of views that normally occur in both applied linguistic and psychoneurolinguistic fields and their individual researchers to interpret changes in the percentages of listening improvement and related test scores over longer time periods. Providing some facts about the study, Shelley-Tremblay and his colleagues have stated: "This study was based on a reading intervention that has previous been found to be effective in a relatively short term intervention, amenable to the juvenile corrections environment." (Shelley-Tremblay, et al., 2012: p. 51)

Furthermore, the current study, according to the researchers, supports the literature suggesting a role for visual attention in reading, and that attention therapy may be an efficient addition to normal educational practices in juvenile detention facilities.

In Erfani (2012)'s study, the author investigated whether a group of people with reading difficulties could read more through visual pictures and compared their performance with those who only read pure texts with no pictures. The author divided the subjects into experimental group and control group. Treatment continued for 12 weeks $(2$ sessions $\times 2$ hours/ day). Results demonstrated good internal efficacy for pictures on reading comprehension. Clarifying this fact, Erfani has obviously stated: "when the readers cannot comprehend a particular passage, they may shift their attention from the text to the accompanying visual images. In return, the visuals, which they do comprehend, might lead them to notice the text's linguistic input and thus enable them to comprehend the text through matching and mapping among factors such as word recognition, syntax, inter-textual perceptions, and background knowledge. The interaction between the text and visuals will 
accordingly facilitate reader comprehension.” (Erfani, 2012: p. 165)

Factor analysis revealed a significant difference between the mean score of the two groups. Significant correlations were found between using texts with pictures and improvement of reading comprehension.

To assess the hypothesis of a limitation in attentional allocation capacity as underlying poor sentence comprehension in children with specific language impairment (SLI), Leclercq, et al., (2013) implemented repeated-measures design with random order of conditions. The research team used 15 children with SLI, 15 age-matched controls, and 15 grammar-matched controls. The subjects under investigation completed a task on comprehending 60 sentences presented in isolation, and 60 sentences presented with a concurrent choice reaction time task in which colored stimuli randomly appeared at the center of the computer screen. Measures of the quality of understanding the written text were taken into account. However, significant differences between the dual-task conditions were detected in the sentence comprehension that was affected by these conditions, and feedback from the subjects in question was to a greater extent. An important result of the study can be clearly seen in the comment of the Leclercq and his team who have clearly observed: "If children with SLI suffer from limitations in processing capacities, they should be less able to efficiently allocate their attentional resources to the various processes involved in a sentence comprehension task." (Leclercq, et al., 2013: p. 266)

These preliminary results, according to Leclercq and his colleagues do not support limitations in attentional allocation capacity as representing a core deficit in SLI. Rather, the data show that these children show attentional allocation capacity comparable to that of younger children having similar language level, suggesting that SLI is characterized by a slowed development of both attentional and language domains.

A brief experimental study, based on the relationship between writing system and recognition strategies, was conducted as a way of understanding whether learners of Japanese with different first language (L1) writing systems use different recognition strategies and whether second language (L2) exposure affects L2 kanji recognition. Matsumoto (2013) used a computerized lexical judgment task with 3 types of kanji characters to investigate these questions: (a) pseudo-homophones, (b) pseudo-homographs, and (c) real words. To this end, the researcher used three groups of learners to investigate the above mentioned relationship. The treatment focused on helping the subjects under investigation to develop more realistic goals and supporting their self-efficacy about their ability to recognize 3 types of kanji characters: Pseudo-homophones, pseudo-homographs, and real words. The results showed significant improvement in the use of reading strategies following treatment and significant outcomes. According to Matsumoto, different reading strategies were used by learners of L1 alphabetic or logographic backgrounds and the beginning and intermediate learners who had had different degrees of exposure to the L2.

Sigrist, et al., (2013) addressed the importance of technical display as means through which motor learning is enhanced, recommending using these audio-visual aids in addition to CALI. According to the research team, such audio-visual aids and CALI are important means that 
should be extensively used for teaching language skills due to their usefulness that can be clearly seen in the EFL students' multimodal feedback. This feedback, the research team adds: "may, therefore, not exclusively facilitate motor learning but, rather, enhance compensatory mechanisms and strategies in order to overcome loss of motor function due to a damaged neuromuscular system. Thus, patients may benefit from augmented feedback in a way that is different from motor learning in healthy individuals..." (Sigrist, et al., 2013: p. 22)

In an increasingly audio-visual and CALI studies, a number of researchers in the field are concerned about giving crucial answers and gratified justifications to sensitive questions. Online computer-based educative programs have been proposed as an accessible means through which some of the questions can be answered. Yet, some questions need further research like "Why does picture naming take longer than word reading?" In Riès, et al., (2012)'s study, the researchers' findings showed that premotor and motor times are both longer in picture naming than in reading, although than in reading, although articulation is already initiated in the latter measure. Providing some specific justifications for the major question they posed in their title, Riès and his colleagues have clearly stated: " one may speculate post-hoc that the articulation of a smaller chunk (e.g., a word onset in reading) will be swifter and more efficient than the articulation of a complete phonetic program (e.g., a whole word in picture naming), but that subsequent execution will be stretched to compensate for a speedy start." (Riès, et al., 2012: p. 960)

Over the past years the correlation between multi-media and language skills' improvement has substantially contributed to the understanding of human and his abilities' correlates. In contrast to other means of media, T.V is well suited to give correct figures about the above mentioned relationship due to its cheap and easy application in all personal and public uses and all educational-related measurement settings. Its importance as a necessary device in peoples' daily life as a means through which they receive their lore allows the researchers to test its fans taste. Notten, et al., (2012)'s review has focused on such complex relationships. The research team concluded that socialization is found to play an indispensable role in the development of both highbrow and lowbrow reading and television tastes. The researchers addressed "both direct and indirect long-term effects of parental socioeconomic status, the example parents set in their own use of media, and the media guidance provided by parents on (adult) children's reading and television viewing tastes." (Notten, et al., 2012: p. 684)

Curriculum-based measurement of reading correlated significantly with both oral and silent reading outcome measures, but no correlations were found for the reading comprehension or understanding. Christ, et al., (2012)'s study showed that progress monitoring outcomes are sufficient to guide educational decisions if (a) ordinary least-squares regression is used to derive trend lines estimates, (b) a very good progress monitoring data set is used, and (c) the data set comprises a minimum of 14 curriculum-based measurement of reading.

Bruhn \& Watt (2012) examined the effects of integrating a multicomponent self-monitoring intervention into a targeted reading classroom. The two researchers used an applied biochemistry and biotechnology (ABAB) withdrawal design developed by Kennedy in 2005 to determine the presence of a functional relation between a multicomponent self-monitoring 
intervention and the academic engagement and disruptive behavior of two middle school girls with reading and behavioral problems. Clearly, Bruhn and his friend provided the teachers and other experts in particular sectors of the field with graded recommendations to be added to the available literature published in such issue.

Soleimani \&Nabizadeh (2012) implemented concept map technique to examine reading proficiency of 90 Iranian pre-university students. In particular, pre-and-posttests for testing reading comprehension were administered to the subjects who were divided into three groups. Treatment continued for three months wherein five sessions have been undertaken. Concept map technique is found to be an influencing strategy. Researchers suggested that such strategy might be regarded as an alternative or even as an effective replacement of the summarizing strategy. Such suggestion is due to some features it has. Soleimani \& Nabizadeh listed some of these features. According to them, "The most important and a basic feature of a $\mathrm{CM}$ is the hierarchical structure. In the process of creating a concept map, the broadest, most inclusive concept should be first determined and written either in the top or in the middle part of the map while detailed concepts will be positioned below the top or around the central concept (as a node). Other concepts which are less important will be deleted or moved away from the map. The other important feature is cross links between separated concept nodes. In drawing a concept map, different kinds of arrows will be used to show the relationship between different concepts. Providing specific examples is the last feature of CM." (Soleimani \& Nabizadeh, 2012: p. 78)

The technique of eye movement during silent and oral reading was assessed by Ashby, et al., (2012). The reliability and validity of the instrument were considered and outcomes compared with those obtained with existing methods. The results, according to Ashby and other members of the research team, revealed that the effects of parafoveal information were larger in silent reading than in oral reading, because of different effects of preview information on both when the eyes move and how often. What happens, according to the researchers, is that "Readers process the word they are fixating and, at some point during that fixation, begin processing the upcoming word to its right. Thus, word recognition during silent reading typically begins when a word appears in parafoveal view to the right of where the eye is fixated." (Ashby, et al., 2012: p. 634)

Additionally, Parafoveal information benefitted silent reading for faster readers more than for slower readers. Computer laboratory, a new technique used at schools for linguistics purposes, is a common method that has been widely applied in most worldwide countries. Contrary to common assumption, this "healthy" educative phenomenon not only manifests itself during computer course or period but also has remarkable effects on the students' everyday classes. Thus, a reliable diagnosis and efficient treatment of this new technique is important to improve the students' educational performances. Nevertheless, to date, using labs for educational purposes is still an underdiagnosed and ill-treated entity, especially when it comes to discuss the use of such important technique in teaching language skills and/ or language components. Based on a systematic literature search, the study of Aydemir \& Öztürk (2012) investigates the use of computer in reading. The two researchers attempted to understand whether or not such method is useful in comparison to the classical way (hard 
copy or printed materials). What motivated the researchers to conduct such research is the fact that "no Turkish study has yet explored the effects of reading from the screen on student motivation, the possible results are open to debate. "This made their study important because "the effects of reading from the screen on reading motivation had not been studied." (Aydemir \& Öztürk, 2012: p. 358)

The performance of reading skill for 30 students read from a computer was evaluated in compared with the same number of students read from printed materials. According to the researchers, outlined results demonstrated that the reading motivation levels of students who read the texts from the screen were significantly lower than those of students who read the printed material, both in the subscales and the overall scale. The number of reliable and valid strategies to measure the effects of some methods on improving reading skill is limited. The purpose of Howe (2012)'s study was to evaluate the newly developed modified eccentric viewing training methodologies, which are, linguistically speaking, a task to assess the effects of rate and speed of reading. The overall findings of the research indicated an association between the earlier techniques with comparable final reading speed. They furthermore provided significant differences in final reading speed between eccentric viewing training methodologies with comparable age subjects. The relationship between age and final reading speed were shown to be negative through correlation analysis. Furthermore, the results demonstrated a correlation between visual acuity and the percentage of change in reading speed.

Azavedo, et al., (2012) tested mammography screening suggested by common European in their annual guidelines as a means through which one can easily read (double reading). The research team investigated the possibility of replacing computer-aided detection (CAD) with a single part of the above mentioned technique. In other words, the equation becomes single reading $+\mathrm{CAD}$. The purpose of conducting such research is to improve reading skill. Smaller changes in the usability of the new technique can be interpreted with only high uncertainty because of the evidence insufficiency to determine whether the accuracy of single reading $+\mathrm{CAD}$ is at least equivalent to that obtained in standard practice. In comparison to double reading, "single reading with CAD gave lower sensitivity $(87.2 \%$ versus $87.7 \%)$ and lower specificity (96.9\% versus 97.4\%)" (Azavedo, et al., 2012: p. 8)

Dyslexia is classified as a psycholinguistic disorder that should be distinguished from alexia. Its recognition is important to both clinical and therapeutic care provided by speech-language therapists (SLTs). Whereas the former is restricted to reading difficulties, the latter involves reading and writing skills. Dexl, et al., (2012) investigated the safeguards that may help protect children from presbyopia, suggesting the inlay in the first year of the child. Recommending this technology for children, the research team has rightly observed: "It has been shown that this technology is a valid and reliable method to evaluate reading speed and reading distance and to calculate reading acuity." (Dexl, et al., 2012: p. 996)

Attempting to determine how audio-visual aids and CALI including Digital versatile disc (DVD) improve reading comprehension, Chen (2012) conducted a quasi-experimental study. Eighty nine EFL students were put in two classes (experimental and control groups) to study 
reading course using audio-visual aids and CALI including DVD. The time of the period is two hours a day and the experiment continued for two months. Having the pre-and-posttests scored and analyzed, the researcher concluded that such aids" significantly increased the scores on the reading comprehension subtests over the control group with exposure to the English language teaching (ELT) textbook." (Chen, 2012: Abstract)

In a uses and gratifications study, Gerlich, et al., (2012) tested the reading motives scale to answer the question "what drives people to read?" Factors analyses were used to reduce the scale items to relatively homogenous factors with descriptive names. These factors, according to the research team, used to describe not only the user motives for consuming the particular medium, but also to predict user's behavior. Such role played by these factors enhanced the researchers to undertake their study. Strictly, researchers believe that "examining reading motivations can strengthen audience activity research.” (Gerlich, et al., 2012: p. 97)

For a more precise analysis, the readers' representations of the main protagonist's emotional status in short narratives were investigated by Gillioz, et al., (2012) over difficulty levels and the rate of change in performance caused by increasing task difficulty. Estimating these representations in addition to several mental factors that may affect these representations was also considered with the respective rate of change in the subjects' level. As expected, the difference between reading times of congruent and incongruent target sentences was bigger in the behavioral than in the emotional condition. Moreover, this pattern was accentuated for high visuo-spatial working memory subjects when they were asked to simulate the stories. The significance of such findings is that they support the idea that mental models may be of a perceptual nature and may more likely include behavioral elements than emotion labels per se.

Strictly, the ability to read texts, stories, books, reports, etc., develop over several months (may be years) and integrate into the various educational and scientific channels and networks. Although adult know how and what to select topics, the specific question of which type of reading (skim/ skip/ fast/ extensive reading vs. scan/ slow/ intensive reading) should one use remains unclear. Such important question motivated Love (2012) to undertake a study on which type of reading one should use and with which text in particular. Consequently, further results of the types of reading providing positive findings in the integrated use of the best way to read and the right method to use (e.g., read aloud easy and more difficult non-words in a predictable alternating sequence, etc.) (Reynolds, et al., 2012) Furthermore, some researchers investigated the issue from another angle. They attempted to understand whether or not a relationship could be drawn from the reading habits of students in both urban and rural colleges (Loan, 2012). Some others prefer to investigate the role of professional books in making this change (Wilson \& Clements, 2012). In fact, such outcomes motivated some researchers to undertake a comprehensive evaluation studies to assess the role of reading to change students' ways of thinking now and then where we benefit from the outcomes in our future reading plans (Ortlieb, 2012). In response to such findings, Breeding (2013) suggested the plan of additional reading and a serious implementation for the references. 
Loan (2012) examined whether online reading through internet surfing contribute to information encoding. By evaluating the responses of 302 internet readers, the researcher found that reading the internet contents normally increase the ability to read fast due to that "It has made its existence, fully or partially, in the reading behavior of the people." (Loan, 2012: p. 2) These findings are dictated by an enhanced results that e-readers prefer religious, sexual, spiritual, and news content than literature content. In order to eliminate such "side effects", Dalton \& Smith (2012) suggested multimodal immersion and strategic reading on the internet where SLTs become designers. In fact, the researchers believe that teachers can tackle this issue. It is expected, Dalton \& Smith add "that teachers will be able to integrate technology effectively into instruction and prepare their students to be creative producers and critical consumers of digital media, resources, and tools." (Dalton \& Smith, 2012: p. 12)

Psychoneurolinguistic articles summarize our current understanding of the clinical features and neuroanatomical and pathologic correlates of audio-visual aids and CALI and their relationship to the performance of the learners who have some language disorders. They also address similarities and differences between students of special needs and those who are suffering from various types of aphasias. Such perspective may be relevant to improving our understanding in the best way of using audio-visual aids and CALI for this class in general. Nikolaraizi, et al., (2013)'s stud, for example, investigated the best ways of using multimedia resources for teaching reading skills to deaf students. One of the important recommendations that can be drawn from the conclusions of the study is that such audio-visual aids along with CALI are necessary due to that "visual literacy" skills enable students to learn how to process visual aids in a way that supports their reading comprehension.

The integrated use of reading and its effects seems to support the separation of two abilities' streams. van Steensel, et al., (2013)'s tested whether this relationship is positive or negative. Two hundreds seventh graders performed a test. Based on the test results of the subjects in question, the possibility of identifying reading comprehension sub-skills and the effects of task specificity on test reliability were examined. The results showed that such task-specific effects did not occur: the reliability of this type of reading was primarily affected by error associated with the score variance within tasks. Regarding the reading tests, the researchers confirmed that "tasks usually consist of texts and questions. Together, test takers' responses to these tasks are taken to provide a valid indication of their ability to understand texts from a particular domain." (van Steensel, et al., 2013: p. 6)

\subsection{Aims of the Study}

This study attempted to test the main and interaction effects of using audio-visual aids and CALI in the performance of students of special needs in reading skill. To this end, the researcher aims to find answers for the following questions:

1. What are the audio-visual aids and CALI that can be used for teaching students of special needs language in general and reading in particular? To what extent can SLTs benefit from them when teaching this class of students? What are the best methods that can be effectively used for implementing these educative aids in a way that guarantee improving students of 
special needs' performances.

2. Compared with those who do not use them, do audio-visual aids and CALI make any difference when they are used for teaching reading skill to students of special needs? Are there any results of other studies that agree or contradict the findings of the present study?

\subsection{Methodology}

Eighty students of special needs (age ranges between 8-18 years old) were enrolled in this experimental study. The subjects were randomly divided into two groups; each group consists of 40 students. Nearly all students suffer different types of aphasias. They underwent a course on reading skill, for a semester (4 months) at al-Malādh school for teaching students of special needs in Dhamar city, republic of Yemen. The purpose of the study was to examine the effectiveness of audio-visual aids and CALI when they are used for teaching receptive skills in general and reading skill in particular. Before and immediately after the first reading lesson, the subjects under investigation performed a pre-test and at the end of the semester, another post-test was administered to them by their SLT who was teaching the two groups at the same school. In between the treatment, the first group studied using audio-visual aids, while the second group studied using ordinary methods (chalk and black boards). Outcomes of the two tests were linguistically and statistically assessed. In this regard, social program for social sciences (SPSS) was implemented to describe the frequencies.

\section{Analysis}

2.1 Using audio-visual aids and CALI for teaching students of special needs language skills in general and reading skill in particular

Educative aids are frequently used in language practice to help students learn very well. Recently, psychoneurolinguists and speech language therapists (SLTs) have realized that using these aids is of special importance to students of speech needs. These divided the practical part of these educational aids into two broad categories:

1. Conventional aids.

2. Computer learning in language teaching.

A very legitimate question that poses itself in this regard is the following:

Why do we use aids in language teaching in general and what are the benefits of using them for students of special needs? To answer such reasonable questions, one needs to understand that aids can be used for many language purposes. Some of these purposes can be listed as follows:

a. Attracting attention (Such feature is good for students of special needs in general and those who are suffering from problems related to cerebration in particular).

b. Maintaining attention (This characteristic is useful for those who are suffering from lethologica). 
c. Clarifying concepts and meanings of words and utterances (notably for those who are suffering from dysac (o) usia).

d. Increasing chances of remembrance (especially if the students are suffering from dysmnesia or impaired memory).

e. Time saving ( 1 picture is worth 1000 words).

f. Adding varieties to class activities.

g. Compensation for the lack of experience in teachers (e.g., bringing pictures for throat to compensate for his inability to draw).

h. Individualizing learning and teaching (e.g., giving students cassettes to be listened to at home or program instruction which takes forms like the book, for example, which is the simplest form and which contains some forms that have some bits of information and each bit of information has its feedback in the margins, etc.

i. Involving learners: Either by asking them to participate in class activities or by using pattern practice which can be done by computer recording. Consider:

- John is reading a book.

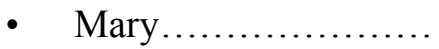

(Instant feedback varies according to the situation e.g., I'm sorry, good answer, well done, excellent, try again, etc.)

j. Presenting authentic language e.g., listening to a native speaker, giving menus to the students, recordings of airport's announcements, news, etc.

k. Simulation of language use (e.g., acting, dramatization, etc.).

Clearly, educational aids can be used for different purposes. We can use them for teaching language skills and language components. In detail, educational aids can be used for teaching oral skills (listening and speaking) and written skills (reading and writing) and components of language (sound system, grammatical structures and vocabulary building). Educational aids for teaching language skills and language components fall into five major types: Visual aids, audio aids, audio-visual aids, action (e.g., dramatization, field trips, debating, etc.), and multi-media (Computer-assisted language learning/ instruction/ teaching (CALL/I/T)).

A: Visual aids: This type takes different forms and shapes:

1- Realia (Real things). This includes chalk, board, chair, etc. (Real things are important for those who are suffering from typhlolexia).

2- Three dimensions models (e.g., trains). (They are important for those who are suffering from myoneuralgia or myoparalysis). 
3- Pictures or drawings: These can be photographic or hand drawn. Pictures in general are useful for those who are suffering from paralogia, nearsightedness, and/ or psychoplegia).There are different types of pictures:

- Simple pictures: Pictures of cars, pens, books, etc.

- Composite pictures: Pictures of scenes in classes, movies, etc.

- Series or sets: For example, telling stories, process of doing something (cooking, manufacturing, experiment, etc.), pictures of transportation means, etc.

4- Posters: Usually consists of picture and text (e.g., posters of "No Smoking"). (These are useful for those who are suffering from paramimia).

5- Maps: These include geographical maps (used for topographical purposes), political maps, city plans, floor plans, etc. SLT can use city plan for example and ask the student who suffers from dyslexia to follow his instructions by drawing lines on the places he/ she is talking about. Maps can also be used for those who are suffering from macropsia).

6- Boards: There are many of them like smart boards, white boards, black boards, etc. (They are suitable for those who are suffering from dysgnosia).

7- Cards: These include flash cards (where the picture is in one side and the word is in the other side), reading cards, and question \& answer cards, etc. (Cards are good for those who are suffering from ebcephalomenigitis or encephalomenigopathy).

8- Graphs: One of the most famous graphs is the pie graphs. Pie graphs are normally used for statistical purposes. (They are also important for students suffering from logokophosis).

9- Forms: To be used by students who are suffering from dysgraphia for example. Examples of forms: Immigration forms, customs forms, hotel forms, etc. (Students who are suffering frpm dyslalia in general find them good where they do not have to speak and all what they have to do is just to write).

10- Menus: Restaurant menus that can be used to teach mentally handicapped students something about cultures, traditions, folklores, etc. (They can be effectively used for those who are suffering from hyperpnea).

11- Slides: Overhead projectors (OHP) slides and $35 \mathrm{~mm}$ slides are some of the example for this type of visual aids. Many of the above mentioned visual aids can be converted into slide forms and then presented to the students of special needs to achieve some class activities. (These are suitable for those who are suffering from hypoesthesia).

12- Film strips: It is a set of slides like picture series. SLTs can also make use of silent films. Logagraphia).

13- Comic books: Examples of this type are children books, stories, etc. that can be used to entertain children, notably those who have problems relating to dyscalculia. Such type also attracts the attention of students suffering from dysarthria and prompts them to speak. 
14- Facial diagrams: Diagrams to be taken from books like phonological books or even by drawing them on the boards for teaching purposes like teaching articulation for those who are suffering from pronunciation problems.

15- Clock, face, and hands: By asking the students to assign the time according to the question or vice versa. Such types of activities help dyscalculic students learn better.

16- Calendars: For counting days of the week, months of the year, numbers, etc. Again, such drill gelps those who suffer from dyscalculia.

17- Letters of the alphabet and numbers: For teaching spelling, recognition of the letter, etc. (Such educative aid is important for those who are suffering from lalling/ lallation).

18- Cross-word puzzle: For teaching vocabularies. We also have scrabbles. Learning vocabulary items is very helpful for those who have developmental aphasia.

19- Tables \& schedules: These include time table, flight schedules, tec. Linking information to each other helps those who have global aphasia as it strengthens their abilities to speak and comprehend.

B: Audio-aids: Some audio aids that can be used for students who have language difficulties are:

1. Cassette recorder or radio: Such audio aid is typical, notably for those who have problems related to Wernicke's aphasia as it helps them comprehend what they are listening to. Those who suffer from conduction aphasia may benefit from these cassettes also as they have to repeat the words and / or phrases they are listening to. In others, they do not have to listen to themselves and repeat their own sentences more than one time.

2. Phonograph records: It is an old version of compact disc (CDs).( These records help those who suffer from dysneuria in general).

3. CDs. (They are good for teaching students of special needs who are suffering from various types of aphasias).

4. Conversional language labs: In this kind of labs, one can have all the above mentioned audio aids. (These labs are convenient for those who are suffering from hypernea or hyperphrenia).

C: Audio-visual aids: The most obvious types are T.V, videos, and also DVD which has almost the same function as the video tape. Sophisticated language lab is another audio-visual aid. In this kind of labs, students of special needs can have both recording and playing. They can also have the facility to speak and listen at the same time and then compare that. Another characteristic of these labs is the facility of instant repetition. Sound movies are also some other types of audio-visual aids. These movies are now replaced by video tapes. Sound movies are the opposite of silent movies. SLTs can mute the sounds so that movies can be functioned for speaking or with the sound for listening. Slide/ sound synchronization is another type of audio-visual aids. In this type, students of special needs can have both sound and picture and this is used to be one of the methods used in the past and is called in French 
"La method audio-visuelle". These educational aids, psychoneurolinguistically, are useful for those who are suffering from language deficits in general and those who are suffering from problems relating to chorda vocalis or chorditis vocalis in particular.

D: Action: This takes different shapes and forms:

1. Dramatization (physical action) like walking, standing up, etc. Such exercises are helpful for students suffering from Alalia. However, if the SLTs notices that his/ her student cannot act the action, then they can ask them (using sign language when necessary) to pantomime or imitate.

2. Charade: Charade is a good exercise due to those students of special needs enjoy it so much. In this type of exercises, SLTs are supposed to play a role of something and their students predict what it is.

3. Party games: Many of them can be used be used as means for teaching language skills in general. In particular, they can be used for teaching those who are suffering from dysphemia and dysthymia.

4. Language teaching games: They can be found in magazines, etc. They are useful for those who are suffering from dysprosody.

5. Field trips: They teach students of special needs some vocabularies. Students of special needs can also get practical experiences with them. Field strips are found to be useful for students who are suffering from dysmimia.

6. Role playing: It is a good example of actions. Such aid is important to those who are suffering from dyslogia.

7. Physical response: It is considered one of the ways of performing actions. This aid is useful for those who are suffering from dyspraxia.

E: Multi-media aids (CALL/ CALT): They are combination of all the above mentioned aids including the use of internet, etc. Nor must we forget some general programs like T.V, radio, etc. SLTs should also pay attention to the use of computer as only one aspect of aids in language learning. It is important, however, that SLTs know the best ways to use the above mentioned educative aids in teaching language to their students of special needs. Some requirements for proper use of these educational aids (selection \& use) are as follows:

- Aim (objective): In this regard, SLT should ask himself/ herself "Why am I using this aid in particular (a picture for instance)? Why not another/ other aid(s)?"

- Effectiveness: Again, SLTs should ask themselves questions regarding to the effects (positive, negative, or side effects). Examples of these questions are: How effective is the use of this educative aid? What shall I do to make that educational aid more effective bearing in mind time, environment, students' levels, individual differences, types of language disorders, etc. For example, a documentary art subject will help students with dysmnesia remember things: Should I use it as a whole or just segment it in sections? When shall I use it? Shall I use it at the beginning, in the middle or at the end of the class? 
- Resources: Questions relating to the availability of the educational aids. These include: Where can I get the educative aid (s)? Are they available in toys' stores, bookstores, or internet?

- Preparation: Making sure whether this educational aid is useable or not (usability of the educative aids and the best way (s) to use it.

Let's take an example of using these educational aids for teaching reading skill for example. Before addressing this issue, there are two aspects that SLTs should consider:

1. Mechanical aspect: It refers to the process where graphic symbols are decoded and dissevered into meaningful unites in the brain and is considered one aspect of reading skill. Unlike Arabic, English has pronunciation marks (every letter does not have its sound). Consider:

$$
\text { F } \quad \text { Ph } \quad \text { FF UGH, etc. }
$$

It should be noted here that the process of converting graphics is not always true. That is, simply speaking, because it can be done without understanding i.e., just by knowing the rules of pronunciations. Regarding the audio-visual aids and CALI that can be successfully used for teaching students of special needs the mechanical reading; one can easily find the letters. Letters as well as numbers can be used on chips, cards (one slide), flash cards (two slides), posters, charts, etc. In fact, realia in general can be typically used as effective audio-visual aids for teaching mechanical reading. A SLT can also make use letters separately/ individually and then ask students of special needs to combine them to make words. OHP as a means of displaying can be used too. SLTs can make use of audio recordings for mechanical reading purposes like asking students, for example, to listen to a passage recorded and then imitate it or just read it loudly. Such drill is useful notably for those who suffer from echolalia, agnosia, dysphrasia, dysecoia, paraphasia and paraphemia. Finally, SLT can display a text and observe how it is read by students of special needs on a computer for example and this can be done gradually (i.e., word by word and line by line).

2. Reading comprehension: It refers to reading skill and normally requires the mechanical aspect. Some of the major requirements for understanding reading skill can be stated as follows:

(a) Discourse markers (beyond sentence level) including headings, sub-headings, titles, indentations, punctuation marks, numbering and all things that should be considered when reading a text.

(b) Cultural issue.

(c) Grammatical structures including reference words, their functions, etc.

(d) Vocabulary items in different contexts (proverbs, idiomatic expressions, phrasia verbs, etc.).

It should be pointed out here that the audio-visual aids and CALI can be used for teaching both reading comprehension (understanding) and training students of special needs in reading comprehension. Looked at it psychoneurolinguistically, some audio-visual aids and CALI can 
be used for one purpose, but some others are used for more than one purpose based on the text. In detail, the text is assigned with visuals like cooking with pictures that will help students of special needs understand and comprehend the text. Certainly, all types of pictures can be used for teaching reading to students of special needs. These include maps, plans, graphs, charts, comic scripts, etc.

Additionally, SLTs can make use of forms (usually for functional reading and also for training learning in reading comprehension). Also, students of special needs are being asked to choose and select from certain types and this drill helps those who are suffering absolute agraphia. Furthermore, time tables can be used where students of special needs (notably those who suffering from paragraphia) are given time table (s) and then asked certain questions in which they provide answers from the time tables they have already given to show their ability in reading and understanding such types of texts. For example, what time is the lesson of reading? Is it on Sunday at 9:00 AM? SLTs can make use of street figures, road signs, building signs, and reading signs (that are used for employer) and all these audio-visual aids and CALI are used for functional reading. Other audio-visual aids that can be used for reading understanding and comprehension include: Audio-visual aids on T.V, streets, etc. SLTs can also make use of action where reading cards, miming, drawing, tracing directions on map, games, etc., are also implemented.

Reading types or say purposes vary: intensive reading (quality, more comprehension, and scanning) where the focus of the reader is on details. In other words, he/ she (the reader) reads a little, but in depth. It is usually described as academic reading and qualitative. On the other hand, extensive reading (quantity, les comprehension, skimming) where the focus of the reader is on the form (pleasure of reading say) like reading from literature sources (genres) in general for example. It is usually described as quantitative reading where the reader reads a lot, but with less depth. Scanning and skimming are, linguistically speaking, are considered sub-skills of reading types. Whereas the former refers to reading for a specific idea or a piece of information, the latter refers to reading for a general idea. Thus, in both cases, the reader does not read everything unlike in intensive and extensive reading where he does.

Concerning extensive reading, SLTs can make use of simplified reading/ readers, and grade them (stories made for different levels of students of special needs based on their learning difficulties and the types of aphasia or language problems they have. For skimming, SLTs can make use of newspapers and magazines. Text books can be used for intensive reading. Again, common audio-visual aids including different types of dictionaries can be used for extensive reading. Surely, dictionaries are good educative aids for reading. Psychoneurolinguistic-wise, using aids for training students of special needs in reading comprehension can be explained in light of the following guidelines and rules:

Firstly, SLT can make use of action aids and these of course include cards with instructions. For example, it is written in the card "Go to the smart board, clean it and come back to your seat." Miming can also be used (e.g., acting the process of swimming for the sentence: He is swimming).Drawing can also be used in case the SLT can draw or at least bring ready-drawings for the lesson/ information he/she wants to present in a particular class. 
Coloring with given instructions is also another way of training students of special needs in reading comprehension. It is useful for those who are suffering from dyschromatopsia (dyschromasia) to help them identify the right color.

Secondly, reading cards can be used. Texts are also given and students of special needs are supposed to match pictures with the texts for practicing reading comprehension. They can also be given a story or a passage (events) by the SLT who is expected to ask them to arrange it according to the events (This can be mostly seen in the newspapers) and the same thing applies to cards. Such exercise is also useful for those who are suffering from aggrammatica (agrammatism).

Thirdly, question-answer (Q-A cards) can be used where each card has a question on one side and an answer on the other side and one student reads the question and the student who has the answer reads it and then he/ she, in turn, reads the question available in his/ her card and so on until the questions and answers are over in the class. Last but not least, it should be noted that it is argued whether or not reading faster increases comprehension. This actually should be taken into consideration by the SLTs to discuss what has been recently known as reading speed comprehension (RSC).

Incidental reading is considered one of the fundamental thing of using CALI like clicking on something, copy, delete, etc. (reading with comprehension) and it happens all the time. However, CALL/CALI/CALT can be involved in teaching reading comprehension to students of special needs and this can be done as follows:

- Acquiring text from the computer either from the net (info site, e-books, periodicals, newspapers, transcripts of broadcast materials, etc.) or from CDs or by using digital cameras/ scanners to capture authentic reading materials (such as signs on roads and other public places, ads, announcements, forms, menus, etc.) to show them to the students of special needs or simply by using optical character recognition (OCR) to digitize and store a text for manipulation. Such means is useful for those who are suffering from aphrasia.

- Displaying a text (along with visuals as pictures, drawings, graphics, maps, etc.). We may use sound facilities for oral form. This method is helpful for those who are suffering from bradypsychia.

- Multiple choice questions/ true/false/ do not know questions (MCQ/T/F/DK), matching text with visuals (pictures, maps, etc.), putting scrambled sentences or paragraphs in the array, choosing/ giving titles, following instructions, short information (Wh-questions). Such method is useful for those who are suffering from aprophoria.

- Providing practice through exercises (with/ without feedback and these exercises include all what has been mentioned earlier. Notice here that SLTs do not have to type anything. All what they have to do is to cut and paste. Notice also that authoring software is a system that gives the SLT different models and guides him/ her to design the lesson. They can use it for teaching those who are suffering from acousmatagnosis.

Regarding the test formats that can be used for reading comprehension, SLTs can make use of 
matching picture with sentences (lists or sets and MC) or matching parts of split sentences (such activity/ drill can be done in reading, not in listening) and it is useful for those who are suffering from auditory and tactile agnosia. MCQ takes different shapes:

1. Correct paraphrase/ interpretation. Consider:

- Had the announcement been made earlier, more people would have attached the lecture.

- Since the announcement was not made earlier, fewer people came to hear the lecture.

2. Information in a passage.

3. Short text, within text (X, Y, Z, etc.). Of course, SLTs should make sure that there must be some sorts of inference. Consider:

- $\quad$ Mary was born in 1980.

- $\quad$ * When was Mary born?

- $\quad$ Mary was 12 in 1980.

- When was she born?

\subsection{Audio-visual aids and CALI: Effects in the performance of students of special needs}

The effectiveness of the use of audio-visual aids and CALI on the performance of students of special needs was evaluated. Such evaluation included not only the treatment group, but also the control group. As is mentioned in the methodology of this research, two comprehensive assessment tests (pre-and-posttests were given to the students in questions. The first test was administered at the beginning of the semester. The following table summarizes the subjects' performances: Consider:

Table 1. Performance of the subjects in the pre-test: Comparison between the treatment and control groups

\begin{tabular}{|c|c|c|c|c|c|c|c|c|}
\hline \multirow[b]{2}{*}{ No } & \multicolumn{4}{|c|}{ Treatment/ Experimental group } & \multicolumn{4}{|c|}{ Control group } \\
\hline & Subject Name & 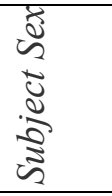 & 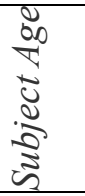 & 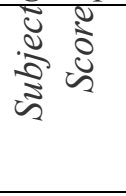 & $\begin{array}{r}\text { Subject } \\
\text { Name }\end{array}$ & 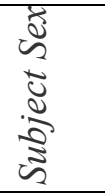 & 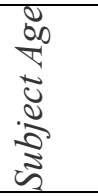 & 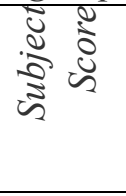 \\
\hline 1 & Saleh & M & 18 & 22 & Nada & $\mathrm{F}$ & 15 & 23 \\
\hline 2 & Majed & $\mathrm{M}$ & 12 & 13 & Hajar & $\mathrm{F}$ & 14 & 18 \\
\hline 3 & Saqr & $\mathrm{M}$ & 14 & 33 & Hamas & $\mathrm{F}$ & 8 & 11 \\
\hline 4 & Ali & M & 8 & 40 & Rashad & M & 12 & 25 \\
\hline 5 & Amatallateef & $\mathrm{F}$ & 12 & 34 & Omar & $\mathrm{M}$ & 9 & 12 \\
\hline 6 & Amatala'leem & $\mathrm{F}$ & 9 & 21 & Ashraf & M & 16 & 9 \\
\hline 7 & Badr & $\mathrm{M}$ & 13 & 19 & Mohammad & $\mathrm{M}$ & 11 & 12 \\
\hline 8 & Tareq & M & 14 & 36 & Montaha & $\mathrm{F}$ & 14 & 27 \\
\hline
\end{tabular}


MInstitute Macrothink $^{\text {Int }}$

Journal for the Study of English Linguistics

ISSN 2329-7034

2013, Vol. 1, No. 2

\begin{tabular}{|c|c|c|c|c|c|c|c|c|}
\hline 9 & Parees & $\mathrm{F}$ & 15 & 38 & Ayman & M & 13 & 16 \\
\hline 10 & Bayrout & $\mathrm{F}$ & 9 & 33 & Aayah & $\mathrm{F}$ & 10 & 13 \\
\hline 11 & Tammaah & M & 9 & 20 & Adham & M & 10 & 30 \\
\hline 12 & Taher & $\mathrm{M}$ & 17 & 23 & Nasser & $\mathrm{M}$ & 11 & 33 \\
\hline 13 & Baraah & $\mathrm{F}$ & 16 & 27 & Haylah & $\mathrm{F}$ & 17 & 35 \\
\hline 14 & Abrar & $\mathrm{F}$ & 11 & 29 & Tawfeeq & $\mathrm{M}$ & 13 & 27 \\
\hline 15 & Ahmad & M & 13 & 10 & Nour & $\mathrm{F}$ & 12 & 16 \\
\hline 16 & Fatimah & $\mathrm{F}$ & 16 & 2 & Najeebah & $\mathrm{F}$ & 18 & 15 \\
\hline 17 & Amatillah & $\mathrm{F}$ & 18 & 15 & Radha'a & $\mathrm{F}$ & 16 & 12 \\
\hline 18 & Abdullateef & M & 8 & 18 & Wafa'a & $\mathrm{F}$ & 15 & 35 \\
\hline 19 & Amriyah & $\mathrm{F}$ & 12 & 28 & Wajedah & $\mathrm{F}$ & 15 & 40 \\
\hline 20 & Abduljaleel & $\mathrm{M}$ & 12 & 34 & Sultan & M & 9 & 20 \\
\hline 21 & Kareemah & $\mathrm{F}$ & 11 & 32 & A'simah & $\mathrm{F}$ & 12 & 22 \\
\hline 22 & Nadiyah & $\mathrm{F}$ & 11 & 17 & Adalah & $\mathrm{F}$ & 11 & 19 \\
\hline 23 & Sariyah & $\mathrm{F}$ & 13 & 40 & Abulwali & M & 8 & 16 \\
\hline 24 & Sarah & $\mathrm{F}$ & 13 & 39 & A'amal & $\mathrm{F}$ & 8 & 14 \\
\hline 25 & Huda & $\mathrm{F}$ & 18 & 15 & Salah & $\mathrm{M}$ & 12 & 27 \\
\hline 26 & Sulayman & M & 15 & 34 & Ammar & M & 13 & 25 \\
\hline 27 & Amjad & M & 14 & 27 & Luluah & $\mathrm{F}$ & 18 & 39 \\
\hline 28 & Abdullah & M & 11 & 22 & Bilal & M & 14 & 9 \\
\hline 29 & Abdulmajeed & $\mathrm{M}$ & 16 & 17 & Ziad & $\mathrm{M}$ & 12 & 9 \\
\hline 30 & Raghad & $\mathrm{F}$ & 15 & 11 & Ruqayah & $\mathrm{F}$ & 18 & 12 \\
\hline 31 & Hafsah & $\mathrm{F}$ & 14 & 34 & Asma'a & $\mathrm{F}$ & 15 & 13 \\
\hline 32 & Abdurrahman & M & 14 & 26 & Sumayah & $\mathrm{F}$ & 17 & 32 \\
\hline 33 & Akram & M & 14 & 12 & Kawthar & $\mathrm{F}$ & 13 & 23 \\
\hline 34 & Taqwa & $\mathrm{F}$ & 13 & 25 & Khawlah & $\mathrm{F}$ & 14 & 38 \\
\hline 35 & Salma & $\mathrm{F}$ & 12 & 40 & Tasneem & $\mathrm{F}$ & 18 & 40 \\
\hline 36 & Hadiyah & $\mathrm{F}$ & 18 & 38 & Amal & $\mathrm{F}$ & 10 & 33 \\
\hline 37 & Sayda & $\mathrm{F}$ & 18 & 35 & Sami & M & 10 & 28 \\
\hline 38 & Abdulkareem & M & 16 & 18 & Haneen & $\mathrm{F}$ & 10 & 27 \\
\hline 39 & Sadeq & $\mathrm{M}$ & 8 & 19 & Ayham & $\mathrm{M}$ & 16 & 13 \\
\hline 40 & Motaz & M & 10 & 35 & Sajidah & $\mathrm{F}$ & 18 & 12 \\
\hline $\begin{array}{l}\text { 吾 } \\
\stackrel{0}{\ominus}\end{array}$ & \multicolumn{2}{|l|}{$40(20 \mathrm{M}+20 \mathrm{~F})$} & 530 & 1031 & \multicolumn{2}{|c|}{$40(20 \mathrm{M}+20 \mathrm{~F})$} & 525 & 880 \\
\hline 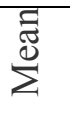 & & - & 13.25 & $25.77 \%$ & \multicolumn{2}{|r|}{--} & 13.12 & $22 \%$ \\
\hline
\end{tabular}

Conducting the analysis of the SPSS in all eighty subjects of the two groups (experimental 
and control group). Of the 80 subjects $(40 \times 40)$, one subject from the treatment group (Fatima) and three subjects from the control group (Ashraf, Bilal, and Ziad) were diagnosed with lower performance levels (below 10 marks). The performance of the other 76 subjects from both experimental and control groups was not utterly different $(25.77 \%, 22 \%$, respectively). Such accurate, reliable and valid results show that the randomization in the process of subjects' selection (methodology) was correct. As is seen, no subject scored more than 50 (all below 50) which means that the level of understanding reading texts for these subjects is below normal standards. Apparently, the females' level is better than that of the males' (553 scores vs. 478 scores). Even with the control groups, the control group of the females seems to have better level than that of the males' (569 scores vs. 311 scores). The whole picture for both males and females becomes clearer when looking at the performance of the subjects under investigation in the posttest. Consider:

Table 2. Performance of the subjects in the post-test: Comparison between the treatment and control groups

\begin{tabular}{|c|c|c|c|c|c|c|c|c|}
\hline \multirow[b]{2}{*}{ No } & \multicolumn{4}{|c|}{ Treatment/ Experimental group } & \multicolumn{4}{|c|}{ Control group } \\
\hline & Subject Name & 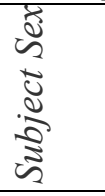 & 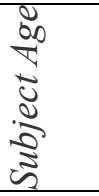 & 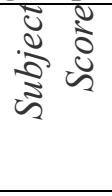 & $\begin{array}{r}\text { Subject } \\
\text { Name }\end{array}$ & 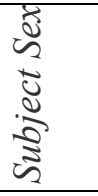 & 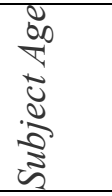 & 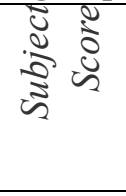 \\
\hline 1 & Saleh & $\mathrm{M}$ & 18 & 49 & Nada & $\mathrm{F}$ & 15 & 23 \\
\hline 2 & Majed & M & 12 & 59 & Hajar & $\mathrm{F}$ & 14 & 18 \\
\hline 3 & Saqr & $\mathrm{M}$ & 14 & 68 & Hamas & $\mathrm{F}$ & 8 & 11 \\
\hline 4 & Ali & $\mathrm{M}$ & 8 & 79 & Rashad & $\mathrm{M}$ & 12 & 25 \\
\hline 5 & Amatallateef & $\mathrm{F}$ & 12 & 89 & Omar & $\mathrm{M}$ & 9 & 12 \\
\hline 6 & Amatala'leem & $\mathrm{F}$ & 9 & 98 & Ashraf & $\mathrm{M}$ & 16 & 9 \\
\hline 7 & Badr & $\mathrm{M}$ & 13 & 67 & Mohammad & $\mathrm{M}$ & 11 & 12 \\
\hline 8 & Tareq & $M$ & 14 & 57 & Montaha & $\mathrm{F}$ & 14 & 27 \\
\hline 9 & Parees & $\mathrm{F}$ & 15 & 89 & Ayman & M & 13 & 16 \\
\hline 10 & Bayrout & $\mathrm{F}$ & 9 & 56 & Aayah & $\mathrm{F}$ & 10 & 13 \\
\hline 11 & Tammaah & $\mathrm{M}$ & 9 & 58 & Adham & $\mathrm{M}$ & 10 & 30 \\
\hline 12 & Taher & $\mathrm{M}$ & 17 & 59 & Nasser & $\mathrm{M}$ & 11 & 33 \\
\hline 13 & Baraah & $\mathrm{F}$ & 16 & 68 & Haylah & $\mathrm{F}$ & 17 & 35 \\
\hline 14 & Abrar & $\mathrm{F}$ & 11 & 65 & Tawfeeq & M & 13 & 27 \\
\hline 15 & Ahmad & M & 13 & 68 & Nour & $\mathrm{F}$ & 12 & 16 \\
\hline 16 & Fatimah & $\mathrm{F}$ & 16 & 79 & Najeebah & $\mathrm{F}$ & 18 & 15 \\
\hline 17 & Amatillah & $\mathrm{F}$ & 18 & 98 & Radha'a & $\mathrm{F}$ & 16 & 12 \\
\hline 18 & Abdullateef & M & 8 & 96 & Wafa'a & $\mathrm{F}$ & 15 & 35 \\
\hline 19 & Amriyah & $\mathrm{F}$ & 12 & 56 & Wajedah & $\mathrm{F}$ & 15 & 40 \\
\hline 20 & Abduljaleel & M & 12 & 78 & Sultan & M & 9 & 20 \\
\hline 21 & Kareemah & $\mathrm{F}$ & 11 & 75 & A'simah & $\mathrm{F}$ & 12 & 22 \\
\hline
\end{tabular}




\begin{tabular}{|c|c|c|c|c|c|c|c|c|}
\hline 22 & Nadiyah & $\mathrm{F}$ & 11 & 46 & Adalah & $\mathrm{F}$ & 11 & 19 \\
\hline 23 & Sariyah & $\mathrm{F}$ & 13 & 75 & Abulwali & $\mathrm{M}$ & 8 & 16 \\
\hline 24 & Sarah & $\mathrm{F}$ & 13 & 47 & A'amal & $\mathrm{F}$ & 8 & 14 \\
\hline 25 & Huda & $\mathrm{F}$ & 18 & 85 & Salah & $\mathrm{M}$ & 12 & 27 \\
\hline 26 & Sulayman & $\mathrm{M}$ & 15 & 49 & Ammar & $\mathrm{M}$ & 13 & 25 \\
\hline 27 & Amjad & $\mathrm{M}$ & 14 & 98 & Luluah & $\mathrm{F}$ & 18 & 39 \\
\hline 28 & Abdullah & $\mathrm{M}$ & 11 & 67 & Bilal & M & 14 & 9 \\
\hline 29 & Abdulmajeed & $\mathrm{M}$ & 16 & 54 & Ziad & $\mathrm{M}$ & 12 & 9 \\
\hline 30 & Raghad & $\mathrm{F}$ & 15 & 57 & Ruqayah & $\mathrm{F}$ & 18 & 12 \\
\hline 31 & Hafsah & $\mathrm{F}$ & 14 & 68 & Asma'a & $\mathrm{F}$ & 15 & 13 \\
\hline 32 & Abdurrahman & $\mathrm{M}$ & 14 & 87 & Sumayah & $\mathrm{F}$ & 17 & 32 \\
\hline 33 & Akram & M & 14 & 58 & Kawthar & $\mathrm{F}$ & 13 & 23 \\
\hline 34 & Taqwa & $\mathrm{F}$ & 13 & 49 & Khawlah & $\mathrm{F}$ & 14 & 38 \\
\hline 35 & Salma & $\mathrm{F}$ & 12 & 96 & Tasneem & $\mathrm{F}$ & 18 & 40 \\
\hline 36 & Hadiyah & $\mathrm{F}$ & 18 & 90 & Amal & $\mathrm{F}$ & 10 & 33 \\
\hline 37 & Sayda & $\mathrm{F}$ & 18 & 80 & Sami & $\mathrm{M}$ & 10 & 28 \\
\hline 38 & Abdulkareem & M & 16 & 76 & Haneen & $\mathrm{F}$ & 10 & 27 \\
\hline 39 & Sadeq & M & 8 & 50 & Ayham & M & 16 & 13 \\
\hline 40 & Motaz & $\mathrm{M}$ & 10 & 94 & Sajidah & $\mathrm{F}$ & 18 & 12 \\
\hline 苞 & $40(20 \mathrm{M}+20 \mathrm{~F})$ & & 530 & 2837 & \multicolumn{2}{|c|}{$40(20 \mathrm{M}+20 \mathrm{~F})$} & 525 & 880 \\
\hline 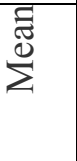 & & -- & 13.25 & $\begin{array}{r}70.9 \\
2 \%\end{array}$ & \multicolumn{2}{|r|}{--} & 13.12 & $22 \%$ \\
\hline
\end{tabular}

In comparison to Table 1, the performance of the subjects in Table 2 is entirely different. Treatment group subjects scored $70.92 \%$ in comparison to $25.77 \%$ in the pre-test. Surprisingly, the performance of the control group in both pre-and-posttests is the same $(22 \%)$. Such difference in the performance of the treatment group is expected due to the involvement of audio-visual aids and CALI in the teaching. Strictly, involvement was based on cause-related effects. Using audio-visual aids and CALI signify that such educative means are necessary in reading comprehension. Modern reading tactics' programs were adopted for the comprehension factor. A computer notebook was used to represent a high involvement and technological aid for the experiment. The scores of the students of special needs who were recruited as experimental subjects vary from the experimental group to the control one.

Statistical analysis shows significance differences in the marks scored by the subjects. The improvement points start from the highest score registered by the treatment group subjects in the pre-test (46). It was even better than that of the control group subjects in the posttest (40). The difference between the performance levels of the experimental and treatment groups 
shows the effect of the treatment tool (audio-visual aids and CALI). Whereas the scores between the weakest and best students in the experimental group is located between 46 and 98, the same scores registered in the control group of the same test (posttest) is located between 9 and 40 . Notice also that only one subject from the experimental group scored 46 (Nadiyah) in comparison to three subjects scored 98 (Amatillah, Amjad and Amatala'leem). On the other hand, only two subjects from the control group scored 40 (Wajedah and Tasneem) in comparison to three students (Ashraf, Bilal and Ziad) whose scores remained the same as they were in the pre-test (below 10). Looking at it psychoneurolinguistically, such lower levels in the subjects in general and in these three subjects in particular is due to the types of aphasia and language disorders these students have (dyslexia and alexia). Regardless the scores registered by the control groups of males and females in both pre-and-posttests which are similar if not the same, the scores of the two sexes are not the same, notably in the posttest. Whereas females scored 1466 marks, males scored only 1371 marks which means that females are, undoubtedly, better than males.

\section{Conclusions \& Recommendations}

Aids to language teaching are of three broad categories: Conventional aids, technological aids (machines other than computer) and CALL. There are some techniques that can be effectively used for teaching language in general. These strategies can be used for teaching nearly all language aspects including the sound system, grammatical structures and vocabulary (language components) as well as teaching the four language skills and culture. Generally, educative aids are of three types. The first type includes visual aids: (e.g., realia, models, pictures/ drawings, posters, maps (geographic and city plans), boards, cards (flash cards, reading cards- Questions \& Answers), graphs, forms, menus, slides (35 mm and OHP), film strips, silent films, comic books and strips, facial diagrams, clock faces and hands, calendars, charts, letters of the alphabet and numbers, cross-word puzzles, etc.). The second type is related to audio aids (including lab) (e.g., audio cassette/ tape (reel) recorders, radio, phonograph records (record albums), CDs, conventional labs. The third type is that of audio-visual aids (e.g., video tapes, TV, DVD, sound films, synchronized audio recording with visual presentations (slides), action aids (e.g., dramatization, field trips, games, pantomime, etc. ) and multimedia (e.g., CALT/ L), the use of internet, interactive or not, etc.).

A very legitimate question here is: What is the importance of educative aids (Audio-visual aids and CALI) in speech language pathology? To answer such question, SLTs need to know the characteristics and benefits of audio-visual aids and CALI. Some of these features are relating to attracting attention, maintaining attention. Some SLTs emphasize that audio- visual aids and CALI can be used in matters relating to the clarification of concepts/ meanings of words and utterances. According to these SLTs, these educative aids participate in increasing the chances of remembrance by increasing means of association, saving time, simulation of language use, and presenting authentic language and natural settings for language use. Others add that audio-visual aids and CALI can be exploited to compensate for lack of experience of SLTs, individualize learning and instruction, involve of learners, give variety to the lesson, and provide instant feedback. 
Computers in general and computer programs in particular were found to be successful in achieving transfer of trained language abilities in speed of processing to similar untrained tasks. They can be used as means of presentation of text and also as means of presentation of exercises and feedback (and/or evaluation). Moreover, one can implement them for other educational purposes where they can be effectively used as sources of texts and also as a means of providing a record of students' progress. In addition, computers are the best educative environments where one can easily find all types of electronic dictionaries (e.g., Thesauri, Sakhr, Atlas, Longman, Contemporary, Webster, etc.). Other available electronic references include grammatical/ usage information, information sources (encyclopedia, etc.), and internet access where communication takes place with others. Strictly, internet facilities found to be useful for teaching, references, consultation, interaction with others, practicing through chatting, learning individually or through collaboration (on assignments, etc.).

CALI requires some procedures to be undertaken before therapeutic sessions take place. Standing alone is the first procedure and this refers to two important points: Considering class complementary work, and language course (autonomous learning). Network is another procedure that SLTs should pay attention to. They should make sure that all necessary networks (e.g., local network), internet access, supplementary materials, language course (Autonomous learning), etc., are available. Nor must we forget to add also the feature of benefiting from computer mediated communications (CMC) (e.g., e-mail, chat, distant learning(, information tools ( different topics, language aids like dictionaries, and/ or using computer as a tool (word processing, spell checkers, grammar checker, word count).

Programmed instruction (self-teaching/ learning) can be used to break learning task/ information into small bits, present these in frames which require response by the learner and then provide feedback by the system. In fact, a connection ought to be made between the uses of programmed instruction and CALI since the former is a part of the latter. Such uses of the programmed instruction require us to mention something about the advantages of CALI. These include: Individualization, instant feedback, combining efforts of different experts, assessment, follow-up learner's progress , providing diagnostic report on learners, provision of authentic materials, use of multimedia, combination of different resources (lexical, grammatical, cultural...) and use of corpus linguistic facilities (such as concordancers- key word in context (KWIC)).

Psychoneurolinguistically speaking, human language can be analyzed into sounds (phonemes), words and/ or sentences. These sounds and sentences can be classified into segmental and supra-segmental phonemes and paragraphs. Instant testing/ evaluation of learners' performances are needed here as this gives us instant feedback. Two basic types should not be neglected here that are the linear programming (move on a single track $(1,2$, $3 . .$.$) , and branched/ branching programming: move in different directions, based on$ performance (e.g., Answer A leads to frame 4, Answer B leads to frame 10, Answer C leads to frame 1 , and so forth).

For reading, there are some advices that psychoneurolinguists recommend SLTs on the best way (s) to exploit these audio-visual aids and CALI for their speech language pathological 
programs. However, before applying such educational aids for therapeutic purposes, three important concepts should be first understood:

i. Mechanical aspect: It indicates to the process of converting graphic symbols into sounds/ Deciphering graphic symbols. It also covers letters of the alphabet, writing boards, audio recording, audio-visual recording, OHP, and opaque projector.

ii. Reading comprehension: Some requirements for reading comprehension include the following:

First: Discrimination of graphic symbols.

Second: Understanding lexical items in context.

Third: Understanding grammatical structures (including reference words) and their functions.

Fourth: Recognizing discourse signals/ markers (e.g., transition expressions).

Fifth: Understanding paralinguistic signals (punctuation, different fonts and colors, indentation, numbering, etc.).

Text training/testing involves using two types of educational aids: Visual aids and audio/ audio-visual aids. Visual aids include: pictures (simple, composite, sets or series), drawings, graphs, maps, slides, film strips, comic strips, forms, timetables, menus, signs, ads, word/ text cards (e.g., Q \& A cards), OHP, opaque projector, etc. Unlike visual aids, audio-audio-visual aids covers all the above mentioned means in addition to the action (reading cards with instructions, acting, miming, drawing, tracing on a map, games, etc. Four types of reading, strictly speaking, should be comprehensively understood by the SLTs before they start using the earlier educative aids for their students of special needs: Intensive, extensive (aids: simplified and/ or graded readers), scanning and skimming (newspapers and magazines).

\section{iii. Reading speed}

It refers to pacers, and software that can be used for speed reading.

Before talking about the audio-visual aids and CALI that SLT could make use of when teaching reading comprehension to their students of special needs, he or she must have understood first what is meant by incidental reading. According to Baylor, Incidental learning is "some form of indirect / additional / unplanned learning within an informal or formal learning situation. It is also used to describe informal learning, but that should be avoided." (Baylor, 2001: pp.227-228)

Looked at it from a psychoneurolinguistic point of view, incidental reading takes six (6) various different shapes:

- Acquiring texts from the computer: This, in turn, includes the net (info sites, e-books, periodicals, newspapers, transcripts of broadcast materials, CDs, using digital cameras/ scanners) to capture authentic reading materials (such as signs on roads and other public places, 
ads, announcements, forms, menus, etc.) to show to students of special needs, and using OCR to digitize and store a text for manipulation.

- To display texts (along with visuals, as pictures, drawing, graphs, map, etc.). We may use the sound facilities for the oral form.

- To provide practice through exercises (with or without feedback): This covers all types of MCQ, T/F/DK, matching text with visuals, putting scrambled sentences or paragraphs in order, choosing titles, short information questions (WH-questions).

The test formats that can be used in this type vary depending upon what ideas/ objectives in particular SLTs want to examine. Some of these are:

- Matching pictures with sentences (lists or sets and MC) OR match parts of split sentences.

- $\quad$ T/F OR T/F/DK (don't know) OR identifying the correct statements, based on picture and graphs, text, or common knowledge/ facts.

- Multiple choice questions (MCQ): For example, short text, within text (... (x,y,z)..), correct paraphrases/ interpretations, information in a passage, etc. (Answers are not to be directly found in text)

- Short answer questions (Wh-questions).

- Completion items (word/ phrase).

- Cloze test: Blanks (systematic/ specific). This could be done in different ways like a text, delete every fifth/sixth word; answer from student or from multiple choices (between parentheses). Alternatively, they could be from a list alongside, at the top or bottom of text, from short lists (one for each paragraph) or from sets of words grouped together (e.g. nouns, verbs, prepositions, pronouns, etc.).

- Re-arranging paragraphs (e.g., giving/ choosing: titles, comments, descriptions, based on passage). Feedback may be provided in a separate file.

iv. Providing help, lexical or information.

v. Practicing research of different levels (using the internet).

vi. Reading speed.

As is mentioned in the methodology of the research, 80 subjects were randomly assigned to the current experimental study. All audio-visual aids and CALI used in the study were found to have significant effects on improving reading understanding of the subjects under investigation. The performance levels of the students of special needs were found to be higher in the treatment group than in the control group. This can be clearly observed in the means of the scores in both pre-and-posttests $(22 \%$ for the control group in both pre-and-posttests) in comparison to $25.77 \%$ and $70.92 \%$ for the treatment/ experimental group. Such scores can be clearly seen in light of the following figure. Consider: 


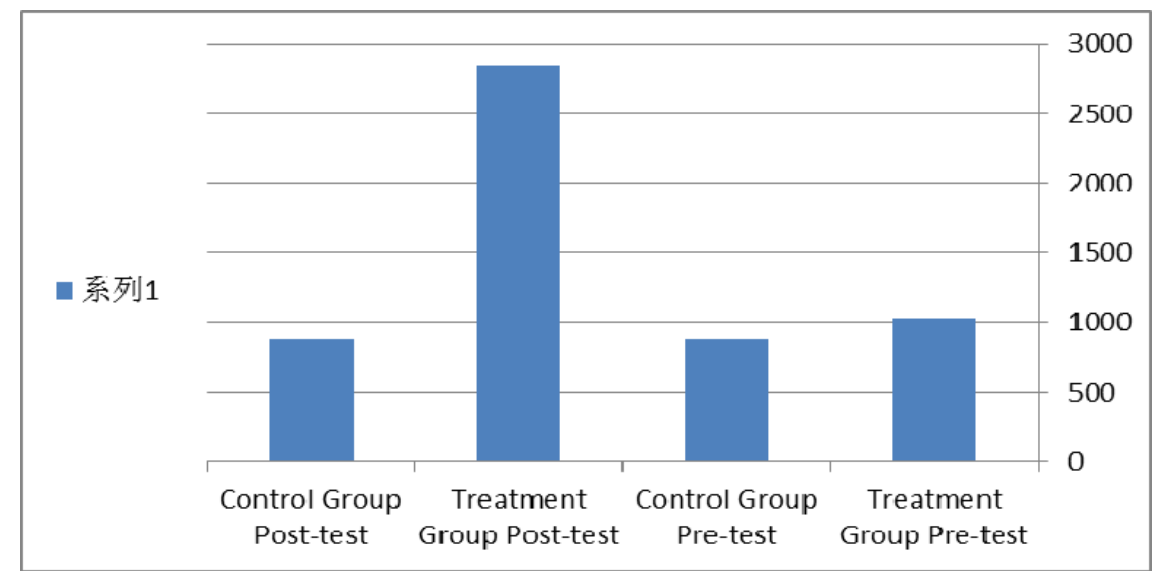

Figure 1. Treatment/ Experimental group and control group's pre-and-posttests: Outcomes' comparison

As can be seen in the figure, the performance of the subjects in the post test is incomparable. These outcomes suggested that audio-visual aids and CALI's involvement had a positive effect on the performance of the subjects under investigation. This positive effect was clearly found in the posttest where subjects' scores reached 71\%. Such outcomes agree with the results of many other studies (Wolf, et al., 2012; Ismail, et al, 2012; Anson \& Schwegler, 2012; Manoli \& Papadopoulou, 2012; Fuenzalida \& Sjöberg, 2012; Shelley-Tremblay, et al., 2012; Chen, 2012; Aydemir \& Öztürk, 2012; Damoiseaux, et al., 2012; Álvarez, 2012; Pavan \& Baggio, 2013; Chen \& Yen, 2013; and Nikolaraizi, et al., 2013).

Compared with males, females scored higher scores. Such fact can be clearly in the outcomes of the posttest where females scored 1466 scores while males scored only 1371 scores. Figure 2 illustrates these findings. Compare:

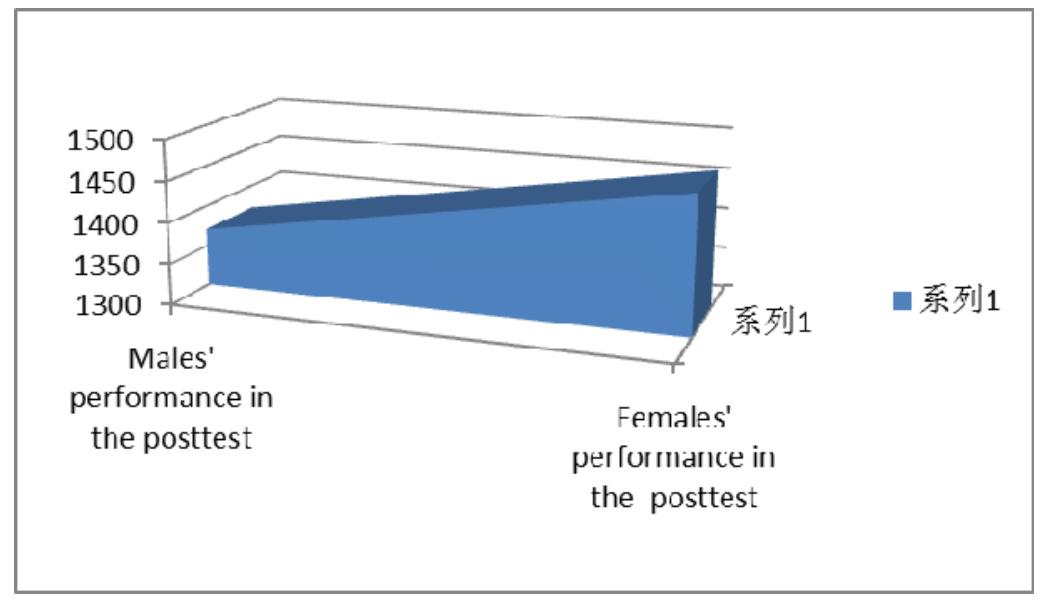

Figure 2. Performance of males and females in posttest

As can be clearly seen in figure 2 , the level of females is better than that of the females. This 
may be accounted for because of the fact that they feel close to their teacher who is female too.

\section{Acknowledgement}

This research would not have been possible without the guidance and the help of Prof. Kebbe who in one way or another contributed and extended his valuable assistance in the preparation and completion of this study.

\section{References}

Ahmed, S. S. (2012). Media pedagogy - the medium is the message. Paper presented at the (64), 425-430. Retrieved from http://search.proquest.com/docview/1220675367?accountid=44936.

Álvarez, G. (2012). New technologies in the university context: The use of blogs for developing students' reading and writing skills. RUSC, 9(2), 185-198. Retrieved from http://search.proquest.com/docview/1030155853? accountid=44936.

Anson, C. M., \& Schwegler, R. A. (2012). Tracking the mind's eye: A new technology for researching twenty-first-century writing and reading processes. College Composition and Communication, 64(1), 151-171. from http://search.proquest.com/docview/1081830986?accountid=44936.

Ashby, J., Yang, J., Haver, K., Evans, C., \& Rayner, K. (2012). Eye movements and the perceptual span in silent and oral reading. Attention, Perception and Psychophysics, 74(4), 634-640. Retrieved from http://search.proquest.com/docview/1019963831 accountid=44936. http://dx.doi.org/10.3758/s13414-012-0277-0.

AYDEMIR, Z., \& ÖZTÜRK., E. (2012). The effects of reading from the screen on the reading motivation levels of elementary 5th graders. TOJET : The Turkish Online Journal of Educational Technology, 11(3), 2-5. Retrieved from http://search.proquest.com/docview/1288346000?accountid=44936.

Azavedo, E., Zackrisson, S., Mejàre, I., \& Heibert-Arnlind, M. (2012). Is single reading with computer-aided detection (CAD) as good as double reading in mammography screening? A systematic review. BMC Medical Imaging, $12(1), \quad 22$. http://dx.doi.org/10.1186/1471-2342-12-22.

Baylor, A. L. (2001). Perceived disorientation and incidental learning in a Web-based environment: Internal and external factors. Journal of Educational Multimedia and Hypermedia Vol. 10/3 , 227-251:2001.

Block, K., Amie, A., Chery, J., Gina, N., Peggy, A., Deborah, W., \& Sara, H. (1993). "Definitions of Communication Disorders and Variations", Ad Hoc Committee on Service Delivery in the Schools. ASHA, 13-14. http://dx.doi.org/10.1044/policy. RP1993-00208, retrieved 2010-08-07.

Bradham, S. T. (2012). From the ear to the brain: Advances in understanding auditory 
function, technology and spoken language development. The Volta Review, 112(2), 149-180. Retrieved from http://search.proquest.com/docview/1095617934?accountid=44936.

Breeding, M. (2013). and additional reading. Library Technology Reports, 49(1), 34-35. Retrieved from http://search.proquest.com/docview/1284655642? accountid=44936.

Brown, A., Stevens, R., \& Pettifer, S. (2013). Making Graph-Based Diagrams Work in Sound: The Role of Annotation. Human-Computer Interaction, 28(3), 193-221. http://dx.doi.org/10.1080/07370024.2012.697010.

Bruhn, A., \& Watt, S. (2012). Improving behavior by using multicomponent self-monitoring within a targeted reading intervention. Behavioral Disorders, 38(1), 3-17. Retrieved from http://search.proquest.com/docview/1293109554?accountid=44936. Applied Biochemistry and Biotechnology. ISSN: 0273-2289. 1559-0291 (Online) http://link.springer.com/journal/12010.

Chen, I., \& Yen, J. (2013). Hypertext annotation: Effects of presentation formats and learner proficiency on reading comprehension and vocabulary learning in foreign languages. Computers \& Education, 63, 416-423. http://dx.doi.org/10.1016/j.compedu.2013.01.005.

Chen, M. (2012). Effects of integrating children's literature and DVD films into a college EFL class. English Teaching, 11(4), 88-n/a. Retrieved from http://search.proquest.com/docview/1287929804?accountid=44936.

http://education.waikato.ac.nz/research/files/etpc/files/2012v11n4art6.pdf.

Christ, T. J., Zopluoglu, C., Long, J. D., \& Monaghen, B. D. (2012). Curriculum-based measurement of oral reading: Quality of progress monitoring outcomes. Exceptional Children, 78(3), 356-373. $\quad$ Retrieved from http://search.proquest.com/docview/926833518?accountid=44936.

Dalton, B., \& Smith, B. E. (2012). Teachers as designers: Multimodal immersion and strategic reading on the internet. Research in the Schools, 19(1), 12-25. Retrieved from $\mathrm{http}: / /$ search.proquest.com/docview/1284528254?accountid=44936.

Damoiseaux, J., Mallet, K., Vaessen, M., Austen, J., \& Jan-Willem, C. T. (2012). Automatic reading of ANCA-slides: Evaluation of the AKLIDES system. Clinical \& Developmental Immunology, 762874. doi: http://dx.doi.org/10.1155/2012/762874.

Davies, G., \& Higgins, A. (1992). Language and Language Learning. London: CILT.

Devimeenakshi, K., \& Maheswari, C. N. (2012). Using original methods in teaching english language to foreign students (chinese) in indian classroom. English Language Teaching, 5(9), 166-177. Retrieved from http://search.proquest.com/docview/1039540643 ?accountid=44936. http://dx.doi.org/10.5539/elt.v5n9p166.

Dexl, A. K., Seyeddain, O., Riha, W., Hohensinn, M., Rückl, T., Hitzl, W., \& Grabner, G. (2012). Reading performance after implantation of a modified corneal inlay design for the surgical correction of presbyopia: 1-year follow-up. American Journal of Ophthalmology, 153(5), 994-1001.e2. http://dx.doi.org/10.1016/j.ajo.2011.08.044. 
Diaz-Maurin, F., \& Giampietro, M. (2013). A “Grammar" for assessing the performance of power-supply systems: Comparing nuclear energy to fossil energy. Energy, 49, 162-177.

Erfani, S. A. (2012). Pictures speak louder than words in ESP, too! English Language Teaching, 5(8), 164-169. from http://search.proquest.com/docview/1032659495?accountid=44936.

http://dx.doi.org/10.5539/elt.v5n8p164.

Fuenzalida, V., \& Sjöberg, U. (2012). The cultural opportunity of children's television public policies in digital Television/A response to "the cultural opportunity of children's TV: Public policies in digital television". Communication Research Trends, 31 (3), 4-22. Retrieved from http://search.proquest.com/docview/1112924145?accountid=44936.

Gessesse, C., \& Sileshi, L. (2013). The Semiotics of HIV/AIDS Bill-Boards and Their Communication Implications: The Case of Bahir Dar and Gondar Towns in Ethiopia. Online Journal Of Communication \& Media Technologies, 3(1), 240-275.

Gilakjani, A. P. (2012). A study on the impact of using multimedia to improve the quality of english language teaching. Journal of Language Teaching and Research, 3(6), 1208-1215. Retrieved from http://search.proquest.com/docview/1272283949?accountid=44936. http://dx.doi.org/10.4304/jltr.3.6.1208-1215.

Gillioz, C., Gygax, P., \& Tapiero, I. (2012). Individual differences and emotional inferences during reading comprehension. Canadian Journal of Experimental Psychology, 66(4), 239-50. Retrieved from http://search.proquest.com/docview/1269496582?accountid=44936. http://dx.doi.org/10.1037/a0028625.

Gower, L., \& McDowall, J. (2012). Interactive music video games and children's musical development. British Journal of Music Education, 29(1), 91-105. http://dx.doi.org/10.1017/S0265051711000398.

Harcourt, B., \& Templer, B. (2005). "Towards a People's English: Back to BASIC in EIL". Humanising Language Teaching, 1-5.

Henderson, J. M., \& Luke, S. G. (2012). Oculomotor inhibition of return in normal and mindless reading. Psychonomic Bulletin \& Review, 19(6), 1101-1107. Retrieved from http://search.proquest.com/docview/1268714917?accountid=44936.

http://dx.doi.org/10.3758/s13423-012-0274-2.

Howe, J. (2012). Eccentric viewing training and its effect on the reading rates of individuals with absolute central scotomas: A meta-analysis. Journal of Visual Impairment \& Blindness, 106(9), 527-542. Retrieved from http://search.proquest.com/docview/1080970273?accountid=44936.

Iram, S. (2012). Reading needs, facilities and problems of visually impaired people. Pakistan Journal of Library and Information Science, (13), 1-H1. Retrieved from $\mathrm{http}$ //search.proquest.com/docview/1242449874?accountid=44936. Available at http://pu.edu.pk/home/journal/8. ISSN 1680-4465. 
Ismail, A. S., Hamed, M. A., \& Abdurrahman, G. A. (2012). Employing reading and writing computer-based instruction in english as a second language in elementary schools. International Journal of Business and Social Science,3(12), 3-4. Retrieved from http://search.proquest.com/docview/1022655978?accountid=44936.

Khaliq, M. F., Noorani, M. M., Siddiqui, U. A., \& Anwar, M. (2012). Physicians reading and writing practices: A cross-sectional study from civil hospital, karachi, pakistan. BMC Medical Informatics and Decision Making, 12(1), 76. http://dx.doi.org/10.1186/1472-6947-12-76. http://www.biomedcentral.com/1472-6947/12/76.

Kirk, K. I., Prusick, L., French, B., Gotch, C., Eisenberg, L. S., \& Young, N. (2012). Assessing spoken word recognition in children who are deaf or hard of hearing: A translational approach. Journal of the American Academy of Audiology, 23(6), 464-75. Retrieved from http://search.proquest.com/docview/1022698261 ?accountid=44936. http://dx.doi.org/10.3766/jaaa.23.6.8.

Klingenberg, O. G. (2012). Conceptual understanding of shape and space by braille-reading norwegian students in elementary school. Journal of Visual Impairment \& Blindness, 106(8), 453-465. Retrieved from http://search.proquest.com/docview/1034974451?accountid=44936.

Leclercq, A., Majerus, S., Prigent, G., Maillarta, C., \& Gillam, J. O. (2013). The Impact of Dual Tasking on Sentence Comprehension in Children With Specific Language Impairment. Journal Of Speech, Language \& Hearing Research, 56(1), 265-280. http://dx.doi.org/10.1044/1092-4388(2012/10-0290).

Levesque, R. (2007). SPSS Programming and Data Management: A Guide for SPSS and SAS Users, Fourth Edition. SPSS Inc., Chicago Ill. PDF, 1-3. ISBN 1-56827-390-8.

Levy, M. (1997). CALL: context and conceptualisation. Oxford: Oxford University Press.

Loan, F. A. (2012). Reading habits of rural and urban college students iln the 21 st century. Library Philosophy and Practice, 1-10. Retrieved from http://search.proquest.com/docview/1314689519?accountid=44936. ISSN: 1522-0222.

Love, J. (2012). Reading fast and slow. The American Scholar, 81(2), 64-72. Retrieved from http://search.proquest.com/docview/963358664?accountid=44936.

Macleod, A., Fabiano-Smith, L., Boegner-Pagé, S., \& Sami Fontolliet, S. (2013). Simultaneous bilingual language acquisition: The role of parental input on receptive vocabulary development. Child Language Teaching \& Therapy, 29(1), 131-142. http://dx.doi.org/10.1177/0265659012466862.

Manoli, P., \& Papadopoulou, M. (2012). Graphic organizers as a reading strategy: Research findings and issues. Creative Education, 3(3), 348-356. Retrieved from http://search.proquest.com/docview/1022986447?accountid=44936.

http://dx.doi.org/10.4236/ce.2012.33055.

Matsumoto, K. (2013). Kanji Recognition by Second Language Learners: Exploring Effects of First Language Writing Systems and Second Language Exposuree. Modern Language 
Journal, 97(1), 161-177. http://dx.doi.org/10.1111/j.1540-4781.2013.01426.x.

Mead, A. R., Bradwell, R. P., \& Stokes, G. P. (1999). Advanced atlas of autoantibody patterns. Birmingham: The Binding Site. ISBN 0704485109.

Nikolaraizi, M., Vekiri, I., \& Easterbrooks, S. R. (2013). Investigating deaf students' use of visual multimedia resources in reading comprehension. American Annals of the Deaf, 157(5), 458-73. Retrieved from http://search.proquest.com/docview/1314372272?accountid=44936.

Notten, N., Adam, Kraaykamp, \& Konig, R. P. (2012). Family media matters: Unraveling the intergenerational transmission of reading and television tastes. Sociological Perspectives, 55(4), 683-706. doi: http://dx.doi.org/10.1525/sop.2012.55.4.683. http://dx.doi.org/10.1525/sop.2012.55.4.683.

Onnis, L., \& Thiessen, E. (2013). Language experience changes subsequent learning. Cognition, 126(2), 268-284. doi:10.1016/j.cognition.2012.10.008.

Ortlieb, E. (2012). The past, present, and future of reading diagnosis and remediation. Journal of Language Teaching and Research, 3(3), 395-400. Retrieved from http://search.proquest.com/docview/1019434897?accountid=44936.

http://dx.doi.org/10.4304/jltr.3.3.395-400.

Pavan, A., \& Baggio, G. (2013). Linguistic Representations of Motion Do Not Depend on the Visual Motion System. Psychological Science (Sage Publications Inc.), 24(2), 181-188. http://dx.doi.org/10.1177/0956797612450882.

Peek, H. B. (2010). "The Emergence of the Compact Disc". IEEE Communications Magazine 48 (1), 10-17. http://dx.doi.org/10.1109/MCOM.2010.5394021.ISSN 0163-6804.

Peinhardt, R. D., \& Hagler, D. (2012). Peer coaching to support writing development. $\begin{array}{llll}\text { Journal of Nursing } & \text { Education, } & \text { 24-8 }\end{array}$ http://dx.doi.org/10.3928/01484834-20121121-02.

Perea, M. (2012). Revisiting huey: On the importance of the upper part of words during reading. Psychonomic Bulletin \& Review, 19(6), 1148-1153. Retrieved from http://search.proquest.com/docview/1268714918?accountid=44936.

http://dx.doi.org/10.3758/s13423-012-0304-0.

Phelps, R. (1996). "Are US Students the Most Heavily Tested on Earth?". Educational Measurement: Issues and Practice 15 (3), 19-2ro5o4ko4 owi97.

Reynolds, M., Mulatti, C., \& Besner, D. (2012). Reading nonwords aloud: Evidence for dynamic control in skilled readers. Psychonomic Bulletin \& Review, 19(6), 1135-1141. Retrieved from http://search.proquest.com/docview/1268714924?accountid=44936. http://dx.doi.org/10.3758/s13423-012-0290-2.

Riès, S., Legou, T., Alario, B. B., \& Malfait, N. (2012). Why does picture naming take longer than word reading? the contribution of articulatory processes. Psychonomic Bulletin \& Review, 19(5), 955-961. Retrieved from 
http://search.proquest.com/docview/1095372826?accountid=44936.

http://dx.doi.org/10.3758/s13423-012-0287-x.

Shelley-Tremblay, J., Langhinrichsen-Rohling, J., \& John Eyer, J. (2012). Attention therapy improves reading comprehension in adjudicated teens in a residential facility. Journal of Correctional Education, 63(2), 49-67. Retrieved from $\mathrm{http} / / /$ search.proquest.com/docview/1115591553?accountid=44936.

Sigrist, R., Rauter, G., Riener, R., \& Wolf, P. (2013). Augmented visual, auditory, haptic, and multimodal feedback in motor learning: A review. Psychonomic Bulletin \& Review, 20(1), 21-53. Retrieved from http://search.proquest.com/docview/1314366722? accountid= 44936. http://dx.doi.org/10.3758/s13423-012-0333-8.

Smith, B. D. (2004). "Breaking Through: College Reading" 7th Ed. . New York: Longman.

Soleimani, H., \& Nabizadeh, F. (2012). The effect of learner constructed, fill in the map concept map technique, and summarizing strategy on iranian pre-university students' reading comprehension. English Language Teaching, 5(9), 78-87. Retrieved from $\mathrm{http}: / /$ search.proquest.com/docview/1221535900?accountid $=44936$.

http://dx.doi.org/10.5539/elt.v5n9p78.

Swimelar, S. (2013). Visualizing International Relations: Assessing Student Learning Through Film. International Studies Perspectives, 14(1), 14-38. http://dx.doi.org/10.1111/j.1528-3585.2012.00467.x.

Thrasher, A. (1996). "DVD: coming soon to your PC?". Computer Shopper 16 (3), 189.

van Steensel, R., Oostdam, R., \& van-Gelderen, A. (2013). Assessing reading comprehension in adolescent low achievers: Subskills identification and task specificity. Language Testing, 30(1), 3-21. /http://dx.doi.org/10.1177/0265532212440950.

Webster, R., Erdos, C., Evans, K., Majnemer, A., Saigal, G., Kehayia, E., . . . Shevell, M. I. (2008). Neurological and Magnetic Resonance Imaging Findings in Children With Developmental Language Impairment. Journal of Child Neurology vol. 23 issue 8 August 2008, p. 870-877.

Wilson, S. L., \& Clements, K. K. (2012). Exploring the professional books: Alliances, reading as an expert, and community. New England Reading Association Journal, 47(2), 56-62, 80-81. Retrieved

from http://search.proquest.com/docview/940890002?accountid=44936. ISBN-13: 9781416610243.

Wolf, M., Ullman-Shade, C., \& Gottwald, S. (2012). The emerging, evolving reading brain in a digital culture: Implications for new readers, children with reading difficulties, and children without schools. Journal of Cognitive Education and Psychology, 11(3), 230-240. Retrieved from http://search.proquest.com/docview/1124437587? accountid=44936. 


\section{Glossary}

ABAB (Applied biochemistry and biotechnology) = This journal is devoted to publishing the highest quality innovative papers in the fields of biochemistry and biotechnology. The typical focus of the journal is to report applications of novel scientific and technological breakthroughs, as well as technological subjects that are still in the proof-of-concept stage. Applied Biochemistry and Biotechnology provides a forum for case studies and practical concepts of biotechnology, utilization, including controls, statistical data analysis, problem descriptions unique to a particular application, and bioprocess economic analyses. The journal publishes reviews deemed of interest to readers, as well as book reviews, meeting and symposia notices, and news items relating to biotechnology in both the industrial and academic communities. In addition, Applied Biochemistry and Biotechnology often publishes lists of patents and publications of special interest to readers (http://link.springer.com/journal/12010).

ANCA (Anti-neutrophil cytoplasmic antibodies) = These are a group of autoantibodies and monocytes that are detected as a blood test in a number of autoimmune disorders, but are particularly associated with systemic vasculitis. ANCA often "show combinations of both cytoplasmic and perinuclear staining." (Mead, et al., 1999: p.1).

CAD (Computer-aided design) = It is the use of computer systems to assist in the "creation, modification, analysis, or optimization of a design". This software is used to "increase the productivity of the designer, improve the quality of design, improve communications through documentation, and create a database for manufacturing." (Narayan, 2008: pp.3-4).

CALL/I/T (Computer-assisted/aided language learning/instruction/teaching) = It is defined as "the search for and study of applications of the computer in language, teaching and learning." (Levy, 1997: p.1). While CALL is related to students, CALT and CALI "fell out of favor among teachers". In that sense, it can be said that while in the former term, the student-centered approach is the dominant perspective, in the latter; a teacher-centered approach is more preferred. CALI/T exhibits all characteristics of English language teaching (ELT) (Davies \& Higgins, 1992: p.3).

CD $($ Compact Disc) = It is used for storage of data. It was in March 1974, during a meeting of the audio group, two engineers from the Philips research laboratory recommended the use of a digital format on the $20 \mathrm{~cm}$ optical disc, because an error-correcting code could be added." (Peek, 2010: p. 10).

CMC (Computer-mediated communication) $=$ According to McQuail (2005), CMC is seen as "any communication that occurs through the use of two or more electronic devices." (McQuail, 2005: p.1)

DVD (Digital versatile disc) $=$ It is a digital optical disc storage format. The DVD specification provided a storage capacity of $4.7 \mathrm{~GB}$ for a single-layered, single-sided disc and 8.5 GB for a "dual-layered, single-sided disc." (Thrasher, 1996: p. 16).

ESL/ EFL (English as a second/ foreign language) = It can be defined as the use or study of 
English by speakers with different native languages in English speaking countries. Unlike ESL, EFl refers to the teaching of English in a non-English-speaking region. Such differences occurred "during the development of English in the 1930s." (Harcourt \& Templer, 2005: p.2).

KWIC (Key word in Context) = It is considered the most common format for concordance lines "especially in the phrase" (Collins English Dictionary, 2003).

MCQ (Multiple Choice Questions) = It is a form of assessment in which respondents are asked to the best possible answer (s) out of the choices from a list. MCQ, T/F/DK, YES/NO questions and other objective questions are "American English style" (Phelps, 1996: p. 15).

OCR (Optical character recognition) = It is a mechanical or electronic conversion of scanned images of handwritten, typewritten or printed text into machine-encoded text. It is widely used as a form of data entry from some sort of original paper data source (documents, sales receipts, mail, etc.). OCR method, according to Schantz (1982) was "developed in the 1960s and 1970s (Schantz, 1982: p. 4).

OHP (overhead projector) = It is a variant of slide projector that is used to display images to an audience. In the definition of dictionary, "overhead projector is capable of projecting enlarged images of written or pictorial material onto a screen or wall from a transparency placed horizontally below the projector and lighted from underneath"(The American heritage dictionary of the English language, 2009).

RSC (Reading Speed Comprehension) = It is a technique used to improve one's ability to read and comprehend quickly. This strategy was developed by American psychologists. According to Smith (2004) "Speed reading programs are available through courses, both in person or software based, and manuals. While the average adult reading rate is 250 words per minute with 70\% comprehension." (Smith, 2004: p.2).

SLI (Specific Language Impairments) = It is considered one of the commonest causes of childhood developmental disabilities (Webster, et al., 2008: p. 871).

SLTs (Speech-Language Therapists) = They are specialized in communication disorders as well as swallowing disorders. They are also called Speech Pathologists (Block et al., 1993, P. 23)

SPSS (Statistical program/package/product/ for social sciences/ and service solution) $=$ It is a software package used for statistical analysis and is among the most widely used programs for statistical analysis in social science. Levesque (2007) listed some statistical operations that are normally undertaken by SPSS software. These include: "Descriptive statistics (Cross tabulation, descriptive frequencies, exploration, etc.), descriptive ratio statistics, bivariate statistics (means, t-test, ANOVA, Correlation (e.g., bivariate, and partial distances), and nonparametric tests.), and prediction for numerical outcomes (linear regression and prediction for identifying groups (actor analysis, and cluster analysis.)"(Levesque, 2007: p. 392). 


\section{Macrothink

\section{Copyright Disclaimer}

Copyright reserved by the author(s).

This article is an open-access article distributed under the terms and conditions of the Creative Commons Attribution license (http://creativecommons.org/licenses/by/3.0/). 